\title{
A política externa (sub)nacional: um estudo da paradiplomacia do Estado do Rio de Janeiro e de sua relação com o governo federal
}

The (sub)national foreign policy: a case study of the state of Rio de Janeiro paradiplomacy and its relationship with the Federal Government

\section{Fernanda Cristina Nanci Izidro Gonçalves ${ }^{1}$ \\ Patrícia Cabral de Oliveira ${ }^{2}$}

\section{RESUMO}

Este artigo objetiva analisar a paradiplomacia, em especial do Estado do Rio de Janeiro, e identificar como o governo federal, por meio do Itamaraty, vem lidando com esse fenômeno que traz implicações para a política externa brasileira. Conclui-se que, embora a paradiplomacia implique desafios para a coordenação da política exterior, a chancelaria tem se articulado com as unidades subnacionais, percebendo o potencial de ampliar a representação dos interesses nacionais.

Palavras-chave: Política externa brasileira. Paradiplomacia. Estado do Rio de Janeiro.

\section{ABSTRACT}

This article aims to analyze paradiplomacy, especially the state of Rio de Janeiro paradiplomacy, and identify how the Federal Government, through Itamaraty, has been dealing with this phenomenon. It is concluded that although paradiplomacy implies challenges for the foreign policy coordination, Itamaraty has articulated with the subnational units, understanding the potential of increasing Brazilian interests abroad.

Keywords: Brazilian Foreign Policy; Paradiplomacy; State of Rio de Janeiro.

\section{INTRODUÇÃo}

A assinatura do Tratado de Vestfália (1648) concentrou o poder na figura do Estado, que passou a monopolizar a política externa e a ser a única autoridade a ter

\footnotetext{
1 Doutoranda em Ciência Política pelo IESP/UERJ, mestra em Relações Internacionais pela PUC-RJ e graduada em Relações Internacionais pelo Unilasalle-RJ. Atualmente é professora e coordenadora adjunta do curso de Relações Internacionais dessa instituição. Rio de Janeiro, Brasil.

${ }^{2}$ Assessora de Comércio e Investimentos da Subsecretaria de Relações Internacionais do Estado do Rio de Janeiro e graduada em Relações Internacionais pelo Unilasalle-RJ. Rio de Janeiro, Brasil.
} 
legitimidade para firmar acordos e tratados. Entretanto, as últimas décadas do século XX registraram um aumento significativo da atuação de atores não estatais nas relações internacionais, como empresas transnacionais, organizações não governamentais (ONGs) e governos subnacionais ${ }^{3}$, em um contexto marcado por um processo de globalização cada vez mais intenso (VIGEVANI, 2006).

O crescimento considerável do ativismo internacional dos atores não estatais trouxe desafios aos Estados, que buscaram coordenar, por meio de seus ministérios de Relações Exteriores, iniciativas que pudessem competir com as diretrizes nacionais e se adaptar a um cenário de maior descentralização de poder. Nesse campo, destacam-se as intensas atividades internacionais dos governos subnacionais que transformaram a rotina diplomática ao apresentar novas formas de fazer política externa (PRIETO, 2010). Um dos motivos que explicam a crescente atuação externa dos entes federados é a ineficiência dos governos centrais em atender às suas necessidades políticas e econômicas, impulsionando-os a relacionar-se com suas contrapartes ou mesmo com governos centrais de outros Estados e instituições internacionais, como apontado por Vigevani (2006).

No meio acadêmico, o tema tem despertado interesse devido à intensificação do fenômeno, originando uma série de estudos a partir da perspectiva de disciplinas como Direito Internacional, Relações Internacionais e Economia Política Internacional. A atuação externa dos entes federados ficou conhecida como paradiplomacia na literatura acadêmica (DUCHACECK, 1986; SOLDATOS, 1990; PRIETO, 2004).

No Brasil, as pesquisas sobre paradiplomacia ganharam destaque a partir dos anos 2000, com os estudos de Vigevani (2006), Salómon (2011), Sombra Saraiva (2012) e Bessa Maia (2012). No plano prático, desde a década de 1980, os Estados brasileiros praticam paradiplomacia. Nos dias atuais, 22 Estados (dentre os 26 e o Distrito Federal) e 366 municípios brasileiros possuem algum tipo de órgão que trata de relações internacionais, o que demonstra que essa prática não é passageira e suscita a necessidade de entender melhor as atividades envolvidas nessa nova forma de atuação internacional - de caráter subnacional - e quais são os benefícios e possíveis problemas ou tensões

\footnotetext{
${ }^{3}$ Governos subnacionais são "governos (Poder Executivo) das partes constituintes dos Estados nacionais" (BUENO, 2012, p. 5), tais como Estados, municípios, cantões e províncias.
} 
decorrentes dessa prática de política externa em face do governo federal e de seu Ministério das Relações Exteriores (MRE), órgão tradicionalmente responsável pelo encaminhamento das questões externas.

A partir do contexto exposto, este artigo pretende contribuir para o debate acadêmico sobre a paradiplomacia no âmbito brasileiro, destacando, em especial, a atuação externa do Estado do Rio de Janeiro. Com base em uma metodologia explicativa, este artigo propõe discutir o conceito de paradiplomacia, apresentar a atuação internacional do Estado do Rio de Janeiro e identificar como o MRE vem lidando com a crescente paradiplomacia a partir do exame de sua relação com a unidade federada do Rio de Janeiro. Sendo assim, este artigo busca responder às seguintes questões: como o Estado do Rio tem atuado internacionalmente? Como o governo federal, por intermédio do MRE, tem lidado com a paradiplomacia do Estado?

Este artigo está dividido em quatro seções, além desta introdução. A seção a seguir discute e define o conceito de paradiplomacia, apresentando seus impactos para a política exterior brasileira. A terceira seção apresenta a paradiplomacia do Rio de Janeiro. A seção seguinte discute o relacionamento entre o MRE e a entidade subnacional. Por fim, a última seção apresenta considerações finais sobre o tema estudado.

\section{PARADIPLOMACIA: CONCEITO E IMPACTOS}

As pesquisas acerca da atuação internacional de entes subnacionais é algo relativamente recente, tendo surgido em decorrência do debate, na década de 1980, na literatura norte-americana, sobre a existência de um "novo federalismo" que estaria provocando mudanças na atuação dos entes federados. Nesse contexto, Duchacek (1986) e Soldatos (1990), ao notar a atuação internacional dos entes subnacionais, cunharam o termo "paradiplomacia", um neologismo do termo "parallel diplomacy" (AGUIRRE, 1999, p. 185).

Para Duchacek (1986, p. 246), paradiplomacia se refere a ligações políticas que “fazem com que governos não centrais entrem em contato não só com o comércio, com a indústria ou com os centros culturais em outros continentes, mas também com vários ramos ou agências estrangeiras de governos nacionais". Soldatos (1990, p. 46), por sua 
vez, define paradiplomacia como "atividades internacionais realizadas diretamente por atores subnacionais (regiões, comunidades urbanas, cidades) que apoiam, complementam, corrigem, duplicam ou desafiam a diplomacia do Estado-Nação". Nesse caso, o prefixo "para" indica o uso da diplomacia fora da estrutura tradicional do Estado, uma atividade que ocorre em paralelo.

Ao longo do tempo, o debate se intensificou e surgiram críticas ao uso do termo "paradiplomacia". Aguirre (1999, p. 205), por exemplo, discorda do uso do termo e defende que a atuação internacional das unidades subnacionais deveria ser designada "pós-diplomacia" (postdiplomatic) por ser um processo que ocorre além do Estado, ou seja, além da tradicional diplomacia estatal. Hocking (1993, p. 20) critica a ideia de competição e conflito com o governo central implícita no termo paradiplomacia e argumenta que há, na verdade, uma diplomacia de múltiplas camadas (multilayered diplomacy) baseada na interação entre as esferas central e regional. Para o autor, os governos não centrais, mesmo desprovidos de soberania, integram o Estado, o que leva à existência de temas internacionais pertinentes aos âmbitos tanto federal quanto regional.

Prieto (2004, p. 252) trouxe de volta para o debate o termo paradiplomacia com uma nova roupagem:

\begin{abstract}
A paradiplomacia pode ser definida como o envolvimento de governo subnacional nas relações internacionais, por meio do estabelecimento de contatos formais e informais, permanentes ou provisórios ("ad hoc"), com entidades estrangeiras públicas ou privadas, objetivando promover resultados socioeconômicos ou políticos, bem como qualquer outra dimensão externa de sua própria competência constitucional.
\end{abstract}

No Brasil, o debate acadêmico se intensificou por volta dos anos 2000 , trazendo importantes contribuições. Bessa Maia (2012) defende que o neologismo paradiplomacia gera duas interpretações: uma positiva, em que essa atuação pode ser considerada um aditivo à diplomacia clássica, realizada pelos Estados e seus MREs, e outra de conotação negativa, levando a paradiplomacia a ser considerada um desvio da diplomacia.

Há ainda autores nacionais que classificam esse fenômeno como "diplomacia federativa", normalmente se referindo aos programas de incentivo ou constrangimento do governo central à atuação externa de unidades federativas. De acordo com esse viés, Bogéa (2001) defende que a diplomacia federativa é um modo de o governo federal 
coordenar e incentivar as ações internacionais das unidades subnacionais como forma de impulsionar a identificação de novos negócios e novas parcerias na área econômica, política e tecnológica. Miklos (2011) também entende que esse fenômeno pode envolver a coordenação das ações internacionais, mas destaca o constrangimento que incide sobre a ação internacional subnacional, uma vez que sua formulação e implementação pode sofrer limitações do Estado nacional.

Outro termo utilizado para se referir ao fenômeno é protodiplomacia, referindose aos casos em que há uma tendência ao separatismo, fazendo da inserção internacional uma ferramenta de reafirmação de uma identidade própria, como é o caso das regiões Basca e Catalã na Espanha e, por vezes, o Quebéc, no Canadá (CEZÁRIO, 2008).

Em face do extenso debate sobre o conceito, este artigo entende que, embora existam diferentes termos para fazer referência à atuação externa dos entes federados, todos tratam necessariamente da ação internacional das unidades subnacionais, que fazem relações internacionais como forma de perseguir seus interesses regionais - sejam eles voltados à afirmação de uma identidade própria, à captação de recursos financeiros e investimentos ou à busca por cooperação em diferentes áreas. Diante dos diversos termos existentes na literatura, este artigo utiliza o termo paradiplomacia para se referir à atuação externa dos estados que, como apresentado, difere da tradicional diplomacia formulada e coordenada pelo governo federal e seu MRE. No entanto, cabe ressaltar que, levando-se em consideração a experiência brasileira em termos de paradiplomacia, em especial a do Estado do Rio de Janeiro, a relação que se estabelece entre a unidade subnacional e a autoridade formalmente responsável pela condução da política externa não é essencialmente de competição, mas de cooperação.

A ideia de competição aqui mencionada se refere à percepção de que, ao ser uma atividade que se desenvolve em paralelo às atividades de política externa do governo federal, existiria necessariamente uma disputa de interesses que fragmentaria a política exterior, refletindo interesses conflitantes. No entanto, é proposto neste artigo que, no caso do Estado do Rio de Janeiro, a dimensão de conflito é minimizada em detrimento da dimensão de cooperação, que se desenvolve por meio da articulação de uma ação coletiva entre governo federal e unidade subnacional. A relação cooperativa, por sua vez, implica uma coordenação estratégica do MRE em que as ações dos entes subnacionais são 
ajustadas conforme as diretrizes centrais da política externa nacional. Como aponta Farias (2012), o MRE investiu no desenvolvimento de estratégias para coordenação intergovernamental, promovendo e tutelando as iniciativas subnacionais, com o intuito de garantir uma coesão na tratativa dos assuntos exteriores relacionados ao país, integrando as iniciativas subnacionais à identificação dos interesses estratégicos do Brasil em âmbito internacional.

É importante destacar que, além do intenso debate sobre a melhor maneira de se conceituar e definir o fenômeno, há divergências sobre o melhor enquadramento teórico dentro do mainstream das relações internacionais para tratar do tema. Nesse âmbito, a perspectiva da Interdependência Complexa proposta por Keohane e Nye (2001) se apresenta como uma abordagem interessante para observar a atuação externa das unidades subnacionais, surgindo reiteradamente no debate sobre paradiplomacia, como aponta Vigevani (2006). Isso ocorre por ser evidente, nessa linha teórica, a contestação ao modelo do Estado como ator unitário no sistema internacional e o reconhecimento de que as relações internacionais envolvem múltiplos atores e interações. Keohane e Nye (2001) destacam a emergência de atores não estatais desempenhando papéis mais relevantes no cenário internacional, tais como ONGs, companhias multinacionais e a opinião pública internacional, o que dificultaria o controle da política externa por parte dos Estados nacionais.

Apesar de não abordarem especificamente a paradiplomacia, percebe-se que as unidades subnacionais estão entre os novos atores internacionais aos quais Keohane e Nye (2001) fazem referência. Os autores (p. 30) argumentam que não necessariamente o "Estado estará unido quando lidar com governos estrangeiros ou que seus componentes irão interpretar o interesse nacional de forma similar quando negociarem com estrangeiros"4, de forma que o Estado pode se tornar multifacetado. Esse fato poderia, inclusive, trazer dificuldades para os Estados: aqueles em melhor posição para manter sua coerência, com uma tradição política centralizada, teriam melhor capacidade de manipular a interdependência do que Estados fragmentados, mesmo que à primeira vista tenham mais recursos em uma área temática (KEOHANE; NYE, 2001).

\footnotetext{
${ }^{4}$ There is less assurance that the state will be united when dealing with foreign governments or that its components will interpret national interests similarly when negotiating with foreigners (KEOHANE; NYE, 2001, p. 30, tradução nossa).
} 
Trazendo a paradiplomacia para a esfera da política externa brasileira, observase que esse é um fenômeno relativamente recente. Há uma tendência histórica de centralização da política exterior no MRE, conhecido popularmente como Itamaraty. Desde a época do Barão do Rio Branco (1902-1912), discutem-se a continuidade e a coerência na condução dos assuntos externos pelo corpo diplomático, que, mesmo diante de governos com diferentes preferências, soube imprimir, ao menos retoricamente, um grau de continuidade e estabilidade na política externa, demonstrando a existência de uma determinada tradição diplomática (LIMA, 2005; PINHEIRO, 2009). Argumenta-se que, ao longo do tempo, o Itamaraty foi fortalecido enquanto instituição burocrática, ganhando autonomia e legitimando sua condução dos assuntos internacionais (CHEIBUB, 1985). No entanto, nas últimas décadas, tem-se testemunhado a maior participação de outros atores - além do MRE - na formulação da política externa brasileira, sobretudo após o processo de redemocratização, abertura comercial e intensificação da globalização (PINHEIRO, 2009). Essa constatação corrobora a ideia de que a política externa brasileira passa por dois processos nos últimos anos: a verticalização controlada (PINHEIRO, 2009) e a descentralização horizontal (HILL, 2003).

A verticalização controlada, embora não esteja relacionada à paradiplomacia, diz respeito ao aumento da participação da sociedade civil na formulação da política externa. Esse processo é controlado porque existem diferentes níveis de participação da sociedade, com setores que conseguem ser mais influentes e outros menos, o que aponta para um controle dos graus de participação social pela instituição diplomática (PINHEIRO, 2009).

A descentralização horizontal refere-se ao plano do Estado. Hill (2003) argumenta que a burocracia da política externa não está mais confinada aos ministérios das Relações Exteriores, estendendo-se horizontalmente por meio de outros departamentos governamentais, o que provoca problemas de coordenação e controle da política exterior. Essa visão corrobora o caso brasileiro de surgimento de novos atores em outras esferas governamentais, como ministérios que não o de Relações Exteriores, Estados e municípios atuando internacionalmente em prol de objetivos específicos relacionados diretamente aos seus interesses. Seguindo essa mesma linha argumentativa, Pinheiro e Milani (2012) mostram que, apesar de ter sido recorrente a atribuição das 
decisões e das ações de política externa apenas ao Itamaraty, essa situação não corresponde mais à realidade. Os autores enfatizam que as mudanças ocorridas nas últimas décadas do século XX, como o fim da Guerra Fria, as crises financeiras, a revolução tecnológica na área da informação e a intensificação da ação transnacional de redes de ativismo e movimentos sociais, além do aprofundamento da globalização, mudaram as concepções acerca do papel do Estado e de sua prática no âmbito da política externa.

Pinheiro (2009) lembra que nos últimos anos os presidentes da República vêm intensificando a chamada diplomacia presidencial (vide papel desempenhado por Fernando Henrique Cardoso e Lula). Também outros ministérios, como o da Agricultura, da Saúde, da Defesa e da Fazenda, em virtude do surgimento de temas ligados a suas atividades de expertise na agenda internacional do país, vêm ampliando sua participação nas discussões sobre política externa, auxiliando o MRE no tratamento de diversas questões. Dessa forma, diversos ministérios que eram responsáveis por elaborar políticas públicas de teor interno passam a atuar junto ao MRE, ou mesmo de forma mais autônoma, nas relações internacionais. Conforme destaca Pinheiro (2009), as unidades subnacionais (Estados e municípios) passaram a participar de forma mais ativa das relações exteriores, devido, principalmente, ao processo de integração regional com o Mercado Comum do Sul (Mercosul) e à intensificação da cooperação sul-sul. Nesse sentido, outros atores do governo, seja em nível federal, estadual ou municipal, passaram a atuar na elaboração de decisões de política externa, cabendo ao corpo diplomático coordenar as iniciativas para evitar potencial competição com suas diretrizes.

Quanto a essa questão, Pinheiro (2009, p. 16) ressalta que é "relativamente remota a possibilidade de desagregação de agências do Estado conduzindo políticas externas autônomas a serviço de interesses políticos, econômicos ou sociais conflitantes". Isso ocorreria porque o presidente, que possui o poder central em relação à política externa, dificilmente atribuiria a outras instituições, além do MRE, maior autonomia para os assuntos internacionais e também porque, apesar da participação de outros atores, o papel do Itamaraty na formulação e na condução da política externa ainda é central.

Como se observou nesta seção, o termo paradiplomacia não é consensual na literatura e diferentes conceitos foram criados para compreender a atuação internacional dos entes federados conforme se intensificaram as atividades externas dessas entidades. 
Neste artigo, adota-se o termo paradiplomacia para se referir ao fenômeno. A Interdependência Complexa também se apresenta como uma perspectiva analítica relevante para a discussão, por propiciar a análise dos diferentes atores e interesses que existem no mundo globalizado. No âmbito da política externa brasileira, o fenômeno tem sido observado por especialistas que compreendem que a política externa nacional é reflexo de decisões que não estão meramente concentradas no MRE, mas sujeitas à interação e à disputa de diferentes atores, sejam governamentais, sejam do setor privado, como apontado com os fenômenos de descentralização horizontal (no nível do Estado) e verticalização controlada (no nível da sociedade). A paradiplomacia relaciona-se com o processo de descentralização horizontal da política externa, que abre espaços para que outros atores governamentais possam participar da formulação e implementação da política exterior.

\section{A POLÍTICA EXTERNA SUBNACIONAL: O CASO DO ESTADO DO RIO DE JANEIRO}

Em termos de institucionalização da paradiplomacia, o Estado do Rio de Janeiro ocupa a vanguarda no Brasil, com a criação, em 1983, da Assessoria de Relações Internacionais, chefiada por Clóvis Brigagão. Essa assessoria foi criada pelo governador do Estado à época, Leonel Brizola, em virtude de suas ligações com os líderes da Internacional Socialista e dos movimentos trabalhistas na América Latina, Europa, Estados Unidos e África (SOMBRA SARAIVA, 2010). Nesse momento, ainda durante a ditadura militar, houve certa tensão por parte da Presidência da República e do Itamaraty. No entanto, isso nunca chegou a se transformar em confronto (NUNES, 2005).

Na gestão seguinte, de Moreira Franco (1987-1991), continuou-se com uma assessoria do gênero, porém não houve a mesma desenvoltura e ela foi coordenada por um curto espaço de tempo pelo ex-deputado Márcio Moreira Alves (SOMBRA SARAIVA, 2010). Na administração de Marcelo Alencar (1995-1999), as áreas de Cerimonial e Relações Internacionais foram unificadas, sob a chefia de Diva de Múcio Teixeira. ${ }^{5}$

Durante o governo de Anthony Garotinho (1999-2002), a área internacional do Estado foi transformada em um conselho consultivo, chefiado pelo professor Theotonio

\footnotetext{
${ }^{5}$ Subsecretaria de Relações Internacionais da Casa Civil do Estado do Rio de Janeiro. Documentação interna, 2016.
} 
dos Santos. Na gestão de Rosinha Garotinho (2003-2007), o setor de relações internacionais ganhou o status de coordenadoria, liderada pelo professor Antônio Carlos Peixoto. Ambos os órgãos possuíam um perfil acadêmico, voltados para pesquisas e levantamento de informações (SOMBRA SARAIVA, 2010). Nessa época, de acordo com Brigagão (2005), a atuação da coordenadoria era focada, além da pesquisa, em alguns eixos principais, dentre os quais a celebração de acordos internacionais e os debates e pesquisas voltados para a divulgação internacional da imagem do Rio de Janeiro.

Apesar dessa movimentação paradiplomática, a primeira ação empreendida pelo governo federal em prol do tema ocorreu apenas em 1997. Nesse ano, foi criada a Assessoria de Relações Federativas (ARF) do MRE com o intuito de intermediar a relação entre o corpo diplomático e as unidades subnacionais brasileiras por meio da coordenação ou orientação da atuação internacional dos entes federados, ao que se seguiu a criação de escritórios de representação regional do MRE, aprofundando-se, assim, a coordenação da chancelaria brasileira com os governos locais (MIKLOS, 2011).

No governo Lula, a ARF foi transformada em Assessoria Especial de Assuntos Federativos e Parlamentares (AFEPA), em 2003, e foi criada simultaneamente a Subchefia de Assuntos Federativos (SAF) em busca de uma maior cooperação do Executivo com Estados e municípios. De acordo com Costa (2012), essas transformações do Itamaraty ajudaram a consolidar e a conferir legitimidade à dimensão subnacional da política externa brasileira.

Durante o primeiro mandato de Dilma Rousseff, foram lançados dois projetos relacionados à chamada cooperação descentralizada. 0 primeiro foi um edital de convocação para projetos franco-brasileiros de cooperação descentralizada trilateral em benefício do Haiti e dos países do continente africano. ${ }^{6}$ Após esse edital, a iniciativa ganhou mais escopo e, em 2012, foi lançado o Programa de Cooperação Técnica Descentralizada Sul-Sul.7 Ambos os projetos estavam sob a égide da Agência Brasileira de Cooperação (ABC).

\footnotetext{
${ }^{6}$ Disponível em: < http://www.abc.gov.br/imprensa/mostrarnoticia/74>. Acesso em: 31 ago. 2016.

${ }^{7}$ Disponível em: <http://www4.planalto.gov.br/saf-projetos>. Acesso em: 31 ago. 2016.
} 
Tais atitudes por parte do governo central confirmam a descentralização da política externa brasileira e apontam que a paradiplomacia ganhou terreno enquanto prática, tendo sido criada, inclusive, uma área específica no MRE para tratar do tema e coordenar as políticas das unidades subnacionais conforme as diretrizes da política exterior nacional.

No que tange ao Estado do Rio de Janeiro, 2007 foi um marco para a paradiplomacia. Nesse ano, durante a gestão do governador Sérgio Cabral, a área de relações internacionais do Estado ganhou status de subsecretaria, vinculada à Secretaria da Casa Civil por meio do Decreto no 41.324, de 28/5/2008. De acordo com o artigo 57 do Regimento Interno da Casa Civil, de 2013, é de competência da Subsecretaria de Relações Internacionais (SSRI):

I. Planejar, coordenar, integrar, articular e executar as ações do Governo do Estado do Rio de Janeiro no plano internacional, em parceria com as Secretarias de Estado e demais órgãos da administração estadual, do governo federal, das prefeituras e entidades do setor privado;

II. Atuar como interlocutor do Governo do Estado do Rio de Janeiro junto aos atores externos, tais como o corpo consular acreditado no Rio de Janeiro, embaixadas estrangeiras sediadas em Brasília, representações diplomáticas e consulares brasileiras no exterior, organizações internacionais e governos nacionais e subnacionais estrangeiros;

III. Exercer as funções de Secretaria Executiva do Conselho Estadual de Relações Internacionais, órgão colegiado de natureza deliberativa, presidido pelo Governador do Estado do Rio de Janeiro, que reúne Secretarias do Estado, órgãos da administração indireta, representantes convidados do governo federal e entidades representativas do setor privado, visando ao desenvolvimento de uma estratégia estadual de inserção internacional.

A SSRI é dividida em cinco áreas: quatro assessorias temáticas (Cooperação Internacional, Comércio e Investimentos, Financiamentos Externos e Relações Institucionais) e a Assessoria Especial. A divisão em assessorias temáticas foi proposta pela própria equipe que integrava a área internacional estadual, a partir do conhecimento que tinha sobre os principais assuntos de relações internacionais e das possíveis demandas que poderiam receber. A proposta foi aceita pelo secretário da Casa Civil e pelo governador8 à época. Já a Assessoria Especial foi adicionada à estrutura mais tarde.

\footnotetext{
8 SPADALE, Pedro Jorge. Subsecretário da Subsecretaria de Relações Internacionais da Casa Civil do Governo do Estado do Rio de Janeiro. Rio de Janeiro, 24 set. 2014. Entrevista concedida a Patrícia Cabral de Oliveira.
}

Conjuntura Global, vol. 6 n. 1, jan./abr, 2017, p. 94 - 115 
A Assessoria Especial possui uma série de atribuições vinculadas ao suporte direto ao subsecretário. É responsável por gerenciar as atividades administrativas, coordenar a atuação de grupos de trabalho específicos e exercer outras atividades no âmbito de sua função, mediante delegação ou designação do subsecretário. Essa assessoria também é responsável, em conjunto com a Secretaria de Estado do Meio Ambiente e com a Assessoria de Cooperação Internacional, pelo trabalho de planejamento estratégico e acompanhamento das redes internacionais ligadas ao desenvolvimento sustentável das quais o Estado faz parte9: Network of Regional Governments for Sustainable Development (nrg4sd) ${ }^{10}$, Climate Group ${ }^{11}$ e Regions for Climate Action $(\mathrm{R} 20) \cdot{ }^{12}$

A Assessoria de Cooperação Internacional tem como função coordenar, articular, negociar e acompanhar as iniciativas do governo do Estado relacionadas à cooperação internacional descentralizada, assim como atuar em redes e foros mundiais e regionais de governos subnacionais ${ }^{13}$. Sobre essa área, Spadale (2014) esclarece que ela está voltada tradicionalmente para a cooperação recebida, através de capacitação ou assistência técnica ou pela transferência de "boas práticas". A Assessoria de Cooperação Internacional também realiza contatos com agências governamentais. Destacam-se a seguir cinco casos de cooperação entre o Estado do Rio e essas agências:

USAID, norte-americana (jovens em situação social vulnerável nas cidades com menor IDH do Estado, com capacitação para o mercado de trabalho; segurança cidadã); AECID, espanhola (segurança e gestão de emergências e desastres capacitação de policiais, bombeiros e defesa civil); AFD, francesa (mobilidade urbana e planejamento urbano metropolitano integrado); JICA, japonesa (redução de riscos de desastres - prevenção, resposta, mobilização, reconstrução); e GIZ, alemã (cooperação científico-tecnológica em torno de questões energéticas) (SPADALE, 2014, p. 11).

\footnotetext{
9 FRANÇA, Joan Frederick Baudet. Especialista em Políticas Públicas e Gestão da Subsecretaria de Relações Internacionais do Governo do Estado do Rio de Janeiro. Rio de Janeiro, 9 out. 2014. Entrevista concedida a Patrícia Cabral de Oliveira.

10 A nrg4sd foi estabelecida em 2002 no World Summit, em Johannesburgo. Para mais informações: <http://www.nrg4sd.org/>.

11 O Climate Group é uma rede internacional de entes subnacionais focada na baixa emissão de carbono. Para mais informações: <http://www.theclimategroup.org/>.

12 Regions for Climate Action objetiva ajudar os entes subnacionais ao redor do mundo a desenvolver projetos de desenvolvimento econômico de baixo carbono e resiliência climática. Para mais informações: <http://regions20.org/>.

${ }^{13}$ Casa Civil, Regimento Interno. Resolução no 303, de 6/5/2013. Publicado em Diário Oficial dia 7/5/2013. 
Em um breve balanço do período compreendido entre 2007 e 2015, a Assessoria de Cooperação Internacional realizou 44 missões técnicas, enviadas a 22 países, em parceria com 18 secretarias, além das polícias (civil/militar). Em contrapartida, recebeu 101 missões de 28 países e duas organizações internacionais. Além disso, organizou a assinatura de 15 acordos de cooperação internacional pelo governador em temas como promoção comercial, segurança, gestão territorial e desenvolvimento social. ${ }^{14}$

A Assessoria de Comércio e Investimentos, por sua vez, tem como principais atribuições a atração de investimentos externos diretos para o Estado e a promoção do comércio exterior. Essa assessoria possui uma grande articulação com a Secretaria de Estado de Desenvolvimento Econômico, Energia, Indústria e Serviços (Sedeis) e com a Companhia de Desenvolvimento Industrial (Codin) do Estado. Tratando de atração de investimentos no Estado, há atividades que envolvem questões externas e domésticas. As questões externas envolvem a construção da imagem, a inteligência comercial e a organização de outreachs e roadshows ${ }^{15}$, que ficam a cargo da Assessoria de Comércio e Investimentos. Já as etapas domésticas de apoio, acompanhamento após a instalação da empresa e suporte com as questões jurídicas ficam a cargo da Sedeis, da Codin e da Agência Estadual de Fomento (AgeRio) (OLIVEIRA, 2014).

No que tange à promoção comercial, a Assessoria de Comércio e Investimentos coordena o Plano Nacional da Cultura Exportadora (PNCE), lançado em 2012 pelo Ministério do Desenvolvimento, Indústria e Comércio Exterior (MDIC). Atualmente inserido no Plano Nacional de Exportações, busca oferecer ações ligadas à cultura exportadora dos Estados brasileiros por meio da mobilização e capacitação de gestores públicos, empresários de pequeno e médio portes e profissionais de comércio exterior. ${ }^{16}$ A área também lidera a construção de um programa estadual de exportações, denominado Exporta Rio, composto de seis iniciativas que pretendem abarcar desde a construção de materiais de inteligência comercial até o atendimento a micro, pequenos e médios

\footnotetext{
${ }^{14}$ Informações atualizadas com base em registros internos da Subsecretaria de Relações Internacionais.

15 Os outreachs são missões em que o Estado procura se aproximar de empresas cuja presença no Rio é considerada interessante para determinados setores. Já os roadshows realizados no exterior são uma espécie de rodada de negócios em que as empresas são convidadas para ser "apresentadas" ao Estado. Ambos têm como objetivo a atração de empresas e de investimentos diretos e, normalmente, são feitos em parceria com outras secretarias, principalmente a Sedeis, e com instituições como o Sebrae e a Firjan. 16 O PNCE foi reformulado pelo MDIC em 2015 e lançado em 2016. Disponível em:

<http://www.rj.gov.br/web/internacional/exibeconteudo?article-id=2855145>. Acesso em: 22 jul. 2016.
}

Conjuntura Global, vol. 6 n. 1, jan./abr, 2017, p. 94 - 115 
exportadores em parceria com instituições - estaduais e nacionais - que lidam com o comércio exterior. ${ }^{17}$ A existência do programa foi anunciada pelo subsecretário Pedro Spadale durante o evento de lançamento do PNCE no Rio, ocorrido em maio de 2016, mas ele ainda não foi lançado oficialmente pelo governo estadual.

Assim como as outras assessorias, a de Comércio e Investimentos também recebe delegações, especialmente de empresas e de governos estrangeiros (nacionais ou regionais). Apenas entre 2010 e 2015, essa assessoria recebeu 299 missões comerciais, que geraram um potencial de investimentos de aproximadamente US\$13,4 bilhões (US\$ 5,5 milhões dos quais se tem confirmação de concretização) e um potencial de criação de 15.160 empregos (4.250 deles foram confirmados). ${ }^{18}$ Entre as empresas que investiram no estado com participação ativa da Assessoria de Comércio e Investimentos estão a General Electric (GE) (que gerou um investimento direto de US\$ 205 milhões com a construção de um Centro de Pesquisa e Desenvolvimento no Parque Tecnológico Universidade Federal do Rio de Janeiro - UFRJ) e as Trump Towers (investimento estimado em R \$ 3,2 bilhões) (OLIVEIRA, 2014).

A Assessoria de Financiamentos Externos tem suas atividades voltadas para a captação de recursos externos que são destinados a financiar projetos do governo do Estado em suas diversas áreas. Entretanto, a captação de financiamentos externos é uma atividade complexa e geralmente demorada por envolver diretamente o governo federal, necessitando de sua aprovação, já que é a União que cobre a dívida em caso de default. A assessoria trabalha com captação de financiamentos reembolsáveis e não reembolsáveis, além de doações. No período de 2007 a 2015, essa assessoria finalizou 24 projetos de financiamentos reembolsáveis, somando um valor de cerca de US\$ 7 bilhões. Os principais financiadores foram: Banco Internacional de Reconstrução e Desenvolvimento ou Banco Mundial (Bird), Banco Interamericano de Desenvolvimento (BID), Corporação Andina de Fomento (CAF), Agência Francesa de Desenvolvimento (AFD) e Japan Bank for International Cooperation (JBIC) ${ }^{19}$ (OLIVEIRA, 2014).

\footnotetext{
17 Subsecretaria de Relações Internacionais. Documentação interna, 2016.

18 Idem.

${ }^{19}$ Subsecretaria de Relações Internacionais. Documentação interna, 2016.
} 
A Assessoria de Relações Institucionais tem como competências "planejar, preparar e organizar as missões oficiais do governo do Estado ao exterior", "assessorar o governador por ocasião das audiências concedidas às delegações de autoridades estrangeiras em visita oficial ao Rio de Janeiro" e "trabalhar pela divulgação da imagem positiva do Estado no exterior, desenvolvendo, entre outras iniciativas, as relações com os correspondentes de imprensa estrangeira estabelecidos no Rio de Janeiro" (CASA CIVIL, 2013).

Além dos aspectos operacionais decorrentes da realização das missões estrangeiras no Rio ou das missões fluminenses ao exterior, o setor também é responsável pela interlocução com os consulados e embaixadas em questões de natureza protocolar. Ademais, essa assessoria prepara briefings informativos para todas as reuniões internacionais mantidas pelo governador ou vice-governador, com contribuições dos outros setores da subsecretaria (SPADALE, 2014).

Nos últimos anos, têm aumentado as visitas oficiais de autoridades estrangeiras ao Rio de Janeiro, tanto de governos nacionais quanto de subnacionais, além de representantes de organizações internacionais. Dentre os visitantes mais ilustres recebidos pelo Estado, podem-se destacar Barack Obama, Vladimir Putin, príncipe Harry, o primeiro-ministro chinês, Li Keqiang, e até mesmo o papa Francisco (SPADALE, 2014).

A Assessoria de Relações Institucionais foi um setor de movimentação relativamente grande no período 2007-2014. Nesse período, o governador Sérgio Cabral e o então vice, Luiz Fernando de Souza, lideraram 43 missões internacionais (17 países, 69 cidades, 383 agendas e um retorno de US\$ 34 bilhões em investimentos no Estado) e concederam 456 audiências a autoridades internacionais (44\% delas provenientes de países europeus, 24\% das Américas, 12\% da Ásia), além de participarem de 81 eventos internacionais (todos apoiados ou organizados por essa assessoria). ${ }^{20}$ Devido às dificuldades financeiras que afetaram o Estado, nenhuma missão internacional foi realizada em 2015.

Por meio dessa estrutura institucional, a unidade subnacional do Rio de Janeiro busca promover oportunidades de negócios e atrair investimentos para o Estado, além de

${ }^{20}$ Subsecretaria de Relações Internacionais. Documentação interna, 2016. 
ampliar a possibilidade de cooperação e de financiamento externo e a visibilidade do Rio em âmbito externo, ampliando a inserção internacional do Estado.

Após um breve histórico da atuação internacional do Estado do Rio de Janeiro e da apresentação da estrutura, das atividades e dos resultados alcançados pela atual Subsecretaria de Relações Internacionais do Governo do Estado, a próxima seção objetiva analisar a interação entre esse ente federado e o governo central.

\section{TENSÃO OU COOPERAÇÃO NA RELAÇÃO ENTRE GOVERNO FEDERAL E ENTIDADES FEDERADAS?}

Em termos gerais, mesmo quando os Estados investem na projeção de sua imagem no âmbito internacional, essa ação normalmente busca parcerias e investimentos e não independência em questões estratégicas, que sejam discutidas à parte do governo federal. No Brasil, as decisões estratégicas de política externa são exercidas exclusivamente pelos agentes diplomáticos. Os Estados e municípios brasileiros não têm ingerência na definição das metas e estratégias da política exterior brasileira e não é comum que os entes subnacionais se posicionem sobre acontecimentos internacionais, muito menos de maneira distinta das notas oficiais do MRE. Seguindo a linha argumentativa de Sálomon e Nunes (2007), excluídas as questões afetadas à alta política (questões estratégicas), as áreas internacionais das unidades subnacionais se articulam ao redor de duas dimensões temáticas: a promoção econômica e a cooperação política e técnica.

A promoção econômica conta com amplo apoio institucional de órgãos federais como a Agência Brasileira de Promoção de Exportações e Investimentos (Apex) e a Rede Nacional de Informações sobre Investimento (Renai), que, além de manter contato com os Estados a esse respeito, promove cursos de capacitação técnica. ${ }^{21}$ No que tange às

\footnotetext{
21 Um exemplo desses cursos é o Workshop de Promoção de Investimentos Internacionais, oferecido pelo FDI Intelligence em parceria com o Ministério do Desenvolvimento, Indústria e Comércio Exterior (MDIC), a Confederação Nacional da Indústria (CNI) e a Rede Nacional de Informações sobre Investimento (Renai), em Brasília, em outubro de 2015. É possível ver a programação em: <http://arquivos.portaldaindustria.com.br/app/conteudo_13/2015/08/26/1533/Programao6Seminriod eCapacitaoemAtraodeInvestimentos.pdf>. Acesso em: 22 jul. 2016. Em 2016 ocorreu, na sede da Agência Brasileira de Promoção de Exportações e Investimentos (Apex-Brasil), o workshop Promoção de Investimentos Estrangeiros e Modelo de Ombudsman de Investimentos da Coreia do Sul, que contou com apoio do Banco Interamericano de Desenvolvimento (BID) e da Confederação Nacional da Indústria (CNI),
} 
exportações, o Ministério do Desenvolvimento, Indústria e Comércio Exterior (MDIC) criou e trouxe para o âmbito do Plano Nacional de Exportações o Plano Nacional de Cultura Exportadora que foi lançado oficialmente em vários Estados. ${ }^{22}$ Essas ações deixam claro o interesse do governo federal nas questões relacionadas à promoção econômica dos entes subnacionais, especialmente os Estados. É interessante notar que há um esforço de coordenação entre os interesses nacionais e os regionais, principalmente em relação ao desenvolvimento.

A cooperação técnica dos governos subnacionais com suas contrapartes (ou mesmo governos centrais) em outros países ocorre normalmente com participação da $\mathrm{ABC}$, a exemplo dos projetos de cooperação descentralizada citados na seção 3 deste artigo. Em termos de cooperação política, é comum que Estados e municípios brasileiros tenham "cidades irmãs" (por meio da assinatura de declarações conjuntas de irmanamento) e assinem memorandos de entendimento com suas contrapartes para cooperar em determinados temas. Entretanto, como não há base jurídica forte para a atuação internacional dos governos subnacionais, esses documentos tornam-se declarações de intenções e não são juridicamente vinculantes (OLIVEIRA, 2014).

Um tema sensível é a captação de financiamentos externos, pois, de todas as ações internacionais subnacionais, é a que possui o maior controle do governo federal, uma vez que a União é avalista dos empréstimos e o processo tem que passar pelo Poder Legislativo. Além disso, a Lei no 9.496, de 1997 (base para a criação da Lei de Responsabilidade Fiscal), possui um forte teor restritivo da capacidade estadual de contratar operações de crédito interno e externo.

A partir disso, é possível observar que o governo federal está atento ao fenômeno da paradiplomacia e vem atuando em conjunto com entidades subnacionais, buscando

também com participação de entes subnacionais. O Estado do Piauí divulgou o evento em sua página na internet: <http://www.piaui.pi.gov.br/noticias/index/categoria/2/id/25202>. Acesso em: 22 jul. 2016.

22 Informações extras sobre o lançamento do PNCE: Paraná < http://www.fiepr.org.br/cinpr/lancamentopnce--plano-nacional-da-cultura-exportadora-5-27033-310759.shtml>, Natal <http://www.apexbrasil.com.br/Noticia/MDIC-LANCA-PLANO-NACIONAL-DA-CULTURA-

EXPORTADORA-EM-NATAL>, Sergipe <http://g1.globo.com/se/sergipe/noticia/2016/04/plano-nacionalda-cultura-exportadora-em-sergipe-e-lancado.html>, Belém <http://www.fiepa.org.br/pt/sala-deimprensa/arquivo-noticias/37-noticias/772-plano-nacional-da-cultura-exportadora-e-lancado-embelem.html> e Rio de Janeiro <http://www.rj.gov.br/web/internacional/exibeconteudo?articleid=2855145>. Acesso em: 22 jul. 2016. 
coordenar a atividade internacional paradiplomática. Se essa atuação do MRE é suficiente ou se há necessidade de um controle maior das atividades subnacionais por parte do governo central, isso é um debate que ainda pode render frutos para a academia e que deve envolver mais estudo empírico sobre o tema.

No que tange ao Estado do Rio de Janeiro, a relação entre a SSRI e o governo federal não é, de modo algum, conflitiva. Apesar de a maioria das atividades da Subsecretaria de Relações Internacionais não exigir autorização expressa da União, a diversidade temática leva ao contato direto e à troca constante de informações com órgãos do governo federal, como MRE, MDIC, ABC, Apex-Brasil, assim como com o Escritório de Representação do MRE no Rio de Janeiro (Ererio) e com a Assessoria Especial de Assuntos Federativos e Parlamentares (Afepa).

Nesse sentido, a SSRI pode ser considerada mais um entre diversos atores governamentais que lidam com assuntos de relações internacionais para além da diplomacia conduzida pelo MRE, como forma de explorar novas oportunidades de cooperação, de investimento e de comércio que se encontram além das possibilidades oferecidas pelo Estado nacional.

\section{CONSIDERAÇÕES FINAIS}

Não é apenas no meio acadêmico que a paradiplomacia está em voga. No Brasil, as áreas de relações internacionais de Estados e municípios têm se multiplicado nas últimas décadas. Como mencionamos, nos dias atuais, grande parte dos Estados e municípios brasileiros possui uma área ou ao menos um assessor para cuidar dos assuntos internacionais. Além disso, os entes subnacionais brasileiros estão vagarosamente se organizando para possuir uma articulação conjunta - vide a existência do Fórum Nacional de Secretários e Gestores Municipais de Relações Internacionais (Fonari) e a recente criação do Fórum de Gestores Estaduais de Relações Internacionais (Fórum RI 27), que já conta com a adesão de dez estados, inclusive do Rio de Janeiro. Desde 2012, há um debate entre as áreas paradiplomáticas subnacionais e a União (representada pela Subchefia de Assuntos Federativos) para a publicação de um decreto 
presidencial visando estabelecer o marco jurídico de cooperação descentralizada no Brasil. $^{23}$

As evidências mostram que não há uma tensão entre os entes subnacionais e o governo federal no que tange aos temas internacionais. Apesar de a paradiplomacia trazer ao MRE o desafio de coordenação de políticas externas, para que sejam relacionadas às prioridades nacionais, ela também propicia um maior ativismo do país em âmbito internacional, por meio da atuação de Estados e municípios. Ademais, promove a captação de investimentos, de financiamentos e de projetos de cooperação que estimulam positivamente a economia e trazem ganhos políticos e sociais.

A descentralização de responsabilidades, em diversas áreas, é uma realidade no Brasil desde a Constituição de 1988 (ARRETCHE, 2002), e no campo das relações internacionais apenas seguiu-se essa tendência. A paradiplomacia se configura como uma nova forma de negociar e representar os interesses de Estados e municípios em âmbito internacional. É uma outra forma de atividade internacional, que se soma à diplomacia tradicional, gerida pelo MRE, e que tem o potencial de ampliar a representação de interesses no campo da política externa e trazer benefícios financeiros, comerciais, turísticos, políticos e sociais para os entes federados e para a sociedade. Se bem coordenada, propicia ganhos múltiplos, unindo os interesses estaduais e/ou municipais às prioridades nacionais. No âmbito brasileiro, essa tendência vem se confirmando, como se observa a partir da relação de cooperação e parceria entre o Estado do Rio de Janeiro e o governo federal, via MRE.

Conclui-se que essa posição de cooperação e não enfrentamento tomada por ambas as partes é o melhor caminho a ser seguido. 0 governo federal pode e deve utilizar a paradiplomacia como uma ferramenta em prol do desenvolvimento local e nacional, já que essa atividade atinge diversas regiões e áreas temáticas que, em muitos casos, ele sozinho tem dificuldades em alcançar.

23 Disponível em: <http://www.portalfederativo.gov.br/articulacao-federativa/assessoriainternacional/eventos-e-reunioes/iii-seminario-e-a-vi-reuniao-da-cooperacao-internacionaldescentralizada-realizados-em-macapa-ap-nos-dias-18-e-19-de-agosto/marco-juridico-saf $>$. Acesso em: 10 jun. 2016. 


\section{Referências Bibliográficas:}

AGUIRRE, Inãkin. Making sense of paradiplomacy? An intertextual enquiry about a concept in search of a definition, Regional \& Federal Studies, v.9, n,1, 1999.

ARRETCHE, Marta. Relações Federativas Nas Políticas Sociais. Educ. Soc., Campinas, v. 23, n. 80, set., 2002.

BESSA MAIA, José Nelson. A paradiplomacia Financeira dos Estados Brasileiros: Evolução, fatores Determinantes, impactos e Perspectivas. Tese (Doutorado em Relações Internacionais) Universidade de Brasília, Brasília, 2012.

SOMBRA SARAIVA, José Flávio. A paradiplomacia financeira no Brasil da República Velha, 1890-1930. Revista Brasileira de Política Internacional, v. 55, n. 1, 2012.

BOGÉA, Antenor Américo Mourão. A diplomacia federativa: do papel internacional e das atividades externas das unidades federativas nos Estados nacionais. Brasília: MRE, 2001.

BRIGAGÃO, Clóvis. Relações internacionais federativas no Brasil: estados e municípios. Rio de Janeiro: Editora Gramma, 2005.

CASA CIVIL, Regimento Interno. Resolução nº 303, de 06/05/2013. Publicado em Diário Oficial dia 07/05/2013.

CEZÁRIO; Gustavo. Atuação Global Municipal: Dimensões e Institucionalização. Dissertação (Mestrado em Relações Internacionais) Universidade de Brasília, Brasília, 2011.

; ANDRADE, Mariana. A cooperação descentralizada no Brasil. Belo Horizonte: CEDIN/CNM, 2008.

CHEIBUB, Zairo Borges. Diplomacia e Construção Institucional: o Itamaraty em uma perspectiva histórica. Dados - Revista de Ciências Sociais, Rio de Janeiro, v. 28, n.1, 1985.

DIAS, Reinaldo. Um tema emergente nas relações internacionais: a paradiplomacia das cidades e municípios, 2010. Disponível em: <http://www.ambitojuridico.com.br/site/index.php?n_link=revista_artigos_leitura\&artigo_id=8156>. Acesso em: 10 mar. 2014.

DUCHACEK, Ivo. The territorial dimension of politics within, among and across nations. London: Westview Press, 1986.

FARIA, Carlos Aurélio Pimenta de. O Itamaraty e a Política Externa: do insulamento à busca de coordenação dos atores governamentais e de cooperação com agentes societários. Contexto Internacional, v.34, n. 1, jan-jun, 2012.

HILL, Christopher. The changing politics of foreign policy. Hampshire/New York: Palgrave, 2003.

HOCKING, Brian. Localizing foreign policy: non-central governments and mutilayered diplomacy. New York: St. Martin’s Press, 1993.

LIMA, Maria Regina Soares de. Aspiração Internacional e Política Externa. Revista Brasileira de Comércio Exterior, n.82, ano XIX, jan-mar, 2005.

KEOHANE, Robert; NYE, Joseph. Power and Interdependence. Longman, 2001. 
MIKLOS, Manoela Salem. Diplomacia Federativa: o Estado brasileiro e a atuação internacional de suas Unidades Constituintes. Carta internacional. v. 6, n. 1, jan.-jun. 2011.

NUNES, Carmen Juçara da Silva. A paradiplomacia no Brasil: o caso do Rio Grande do Sul. Dissertação (Mestrado em Relações Internacionais). Universidade Federal do Rio Grande do Sul: Porto Alegre, 2005.

OLIVEIRA, 2014. Paradiplomacia Econômico-Financeira: O papel do estado do Rio de Janeiro (2007 - 2014). Trabalho de Monografia (Graduação em Relações Internacionais). Unilasalle-RJ: Niterói, 2014.

PINHEIRO, Letícia. Autores y actores de la política exterior brasileña. Foreign Affairs Latinoamérica, v. 9, 2009.

; MILANI, Carlos R S. Política externa brasileira: a política das práticas e as práticas da política (Org.). Editora FGV. Rio de Janeiro, 2011.

PRIETO, Noé Conargo. O outro lado do novo regionalismo pós soviético e da Ásia-Pacífico: a diplomacia federativa além das fronteiras do mundo ocidental. In: VIGEVANI, Tullo; WANDERLEY, Luiz Eduardo; BARRETO, Maria Inês; MARIANO, Marcelo Passini (Org.), A dimensão subnacional e as relações internacionais, São Paulo: Editora da PUC/ Editora da Unesp/ Cedec/ Fapesp, 2004.

. On the Normalization of Sub-State Diplomacy. The Hague Journal of Diplomacy, n.5, 2010.

SALÓMON, Mónica. A dimensão subnacional da política externa brasileira: determinantes, conteúdos e perspectivas. In: PINHEIRO, Letícia; MILANI, Carlos R.S (Org.). Política externa brasileira: a política das práticas e as práticas da política, Rio de Janeiro: Editora FGV, 2011.

; NUNES, Carmen. A Ação Externa dos Governos Subnacionais no Brasil: Os Casos do Rio Grande do Sul e de Porto Alegre. Um Estudo Comparativo de Dois Tipos de Atores Mistos. Contexto Internacional, Rio de Janeiro, v. 29, n.1, jan-jun, 2007.

SOLDATOS, Panayotis. An explanatory framework for the study of federated states as foreign-policy actors. In: MICHELMAN, H.; SOLDATOS, P. Federalism and International Relations: the role of subnational units. Oxford: Clarendon Press, 1990.

SOMBRA SARAIVA, José Luiz. Rio - de sede do reino às olimpíadas: a reinserção do Estado no cenário internacional. Rio de Janeiro: Sistema Firjan, Ed. Especial, 2012.

SPADALE, Pedro. Relações internacionais de unidades subnacionais: a experiência do Estado do Rio de Janeiro. CEBRI, 2014.

SUBSECRETARIA DE RELAÇÕES INTERNACIONAIS DO RIO DE JANEIRO. Documentação Interna, 2016.

VIGEVANI, Tullo. Problemas para a atividade internacional das unidades subnacionais, Estados e municípios brasileiros. Revista Brasileira de Ciências Sociais, v. 21, n.62, out., 2006.

\section{Entrevistas:}

FRANÇA, Joan Frederick Baudet. Especialista em Políticas Públicas e Gestão da Subsecretaria de Relações. Rio de Janeiro, 08 out. 2014. Entrevista concedida à Patrícia Cabral de Oliveira. 
SPADALE, Pedro Jorge. Subsecretário da Subsecretaria de Relações Internacionais da Casa Civil do Governo do Estado do Rio de Janeiro. Rio de Janeiro, 24 set. 2014. Entrevista concedida à Patrícia Cabral de Oliveira. 